\title{
An automated tracer dispersal system for snow accumulation and saltation transport investigations
}

\author{
David A. Braaten and Kenneth L. Ratzlaff \\ Department of Physics and Astronomy and Instrumentation Design Laboratory, The University of Kansas, \\ Lawrence, Kansas 66045
}

(Received 23 June 1997; accepted for publication 28 October 1997)

\begin{abstract}
New automated instrumentation to assess detailed spatial and temporal dynamics of snow accumulation and saltation transport of snow in remote, harsh environments is described. The instrumentation and techniques provide important quantitative, time dependent information which current methods are incapable of providing such as precise dating of accumulated snow layers, snow grain saltation transport distance in wind-swept environments, and characteristics of wind generated surface features. This instrument consists of an ultralow power timing system, a pneumatic system, and microsphere generators to periodically disperse a tracer of colored glass microspheres onto the snow surface. Snow sampling must be conducted before melting occurs, and subsequent identification of microspheres has shown this method is capable of providing accurate dating information with detailed spatial-resolution, as well as characterizing wind blown saltation transport of snow. (C) 1998 American Institute of Physics. [S0034-6748(98)00502-4]
\end{abstract}

\section{INTRODUCTION}

Snow accumulation and snow transport processes are directly relevant to important geophysical concerns such as polar ice sheet growth or decay, ${ }^{1}$ precipitation chemistry, ${ }^{2}$ ecosystem energy balance, ${ }^{3}$ and avalanche hazard. ${ }^{4}$ Wind blown snow transport also has interesting theoretical aspects since it is a multiphase flow system (gas and solid) which exhibits the characteristics of a nonlinear dynamical system by the air flow distorting the surface and producing surface features, which in turn distort the flow. This dynamical system is self-organizational in that it is capable of producing surface features (e.g., ripples) with well defined characteristics which have been studied in both the laboratory and the field. ${ }^{5-7}$

Snow accumulation and transport involve nonlinear interactions between time-dependent physical processes which include episodic precipitation events, wind forces, sublimation, gravitational settling, and snow crystal metamorphosis. To provide quantitative insight into these physical processes and their interactions, an automated instrumentation system has been developed for use in remote areas. This system makes use of a tracer to provide a definitive dating of snow layers which accumulate over a season or longer, to quantify the transport distance of saltating snow grains in wind-swept areas, and to quantify the vertical redistribution of snow grains during the formation of surface features. Current methods of characterizing snow accumulation in terms of relative surface height or snow depth are mainly manual methods, using snow stakes or depth probes, and automated acoustic techniques. ${ }^{8}$ Methods used to determine dates of depositional layers are mainly qualitative and involve visually identifying and estimating the time of formation of snow profile features (e.g., ice layers). ${ }^{9}$ Methods which characterize snow transport are related mainly to mass-flux measurements at fixed locations using either snow grain collection devices ${ }^{10}$ or optical snow grain counting systems. ${ }^{11,12}$ These methods are capable of producing accurate estimates of mass flux but are not suited for long term, unattended operation and cannot provide any estimate of horizontal transport trajectories or the vertical redistribution of snow grains.

\section{INSTRUMENT DESIGN}

The field instrumentation developed for snow accumulation and transport investigations is an automated system which generates and disperses at fixed time intervals an aerosol of colored glass microspheres which gravitationally settle onto the snow surface to act as a time marker and tracer. Primary design considerations for this instrumentation are manageable size and weight of all components, ruggedness, low-temperature operation of all components, and low power consumption to allow its use in harsh, remote polar and alpine environments. The instrumentation, the microsphere dispersal system (MDS), consists of three primary components: solid state timing system; pneumatic system; and microsphere generator units. At preset time intervals, the timing system activates one of four solenoid valves in the pneumatic system, which in turn activates the microsphere generator units.

The timing system circuit, shown in Fig. 1, is designed around a PIC 16CR54 XTI microcontroller (Microchip Technology Incorporated, Chandler, AZ). This device has readonly memory [ROM $(512 \times 12)]$, random access memory [(RAM) $(32 \times 8)]$, input-output ports [I/O (12 bits)] and can be operated at extremely low current over an extended temperature range. Four I/O bits are used to drive the transistor switches for the four solenoids, one bit is used during circuit testing, and one bit is used to drive a low power light emitting diode (LED) indicator. The microcontroller is installed with a low frequency $100 \mathrm{kHz}$ quartz crystal to minimize current consumption which is directly proportional to the 


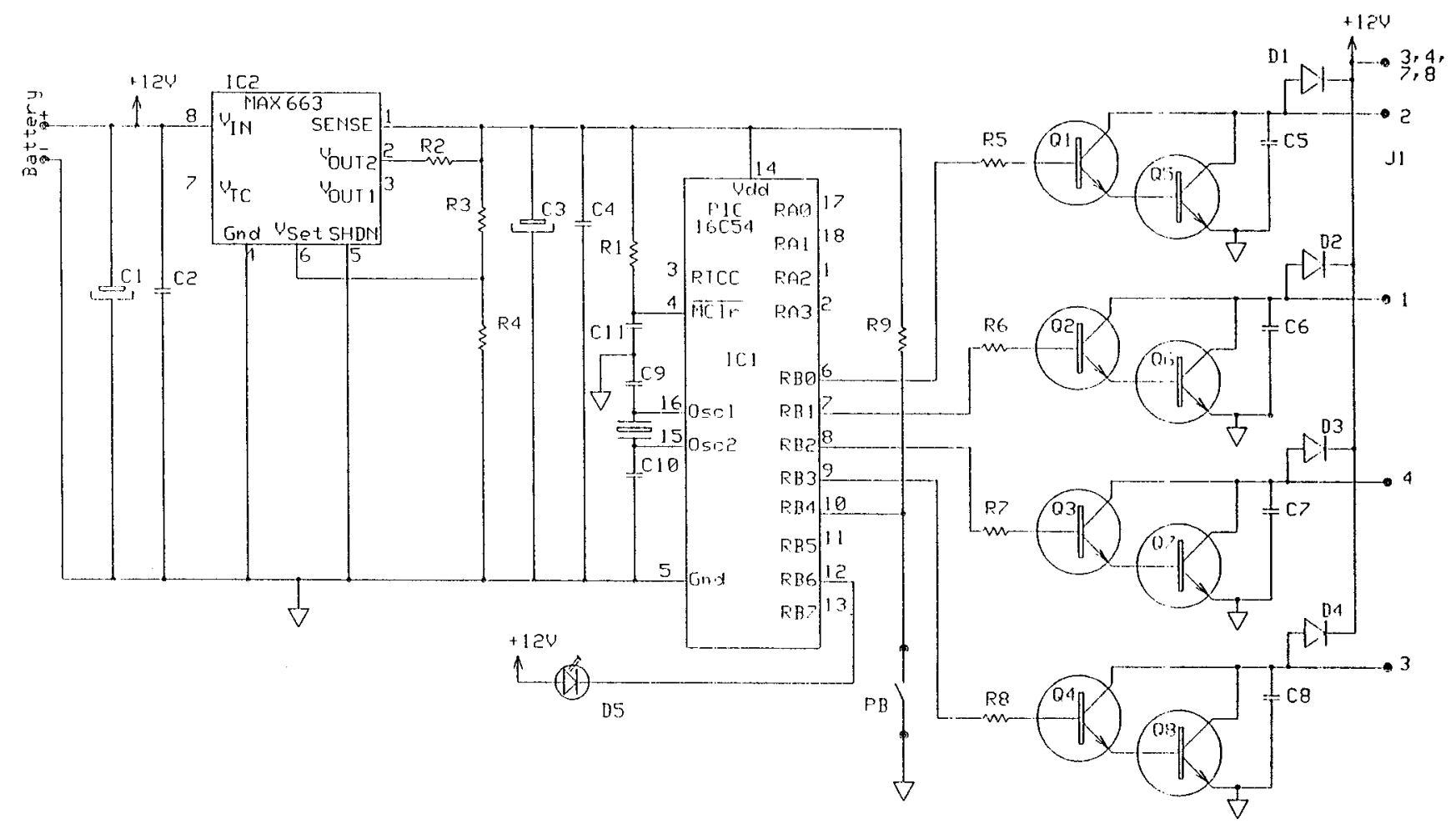

FIG. 1. Schematic diagram of the microcontroller timing circuit.

operating frequency. At this frequency, the microcontroller current consumption measures under $50 \mu \mathrm{A}$. The microcontroller is installed for $+3 \mathrm{~V}$ operation and can operate at voltages down to $+2.5 \mathrm{~V}$. A MAX 663 micropower voltage regulator (Maxim Integrated Products, Sunnyvale, CA) regulates the battery voltage from a $12 \mathrm{~V}$ gel-cell battery (Powersonic, Redwood City, CA) to $+3.1 \mathrm{~V}$. Its advantages over a conventional three-pin regulator are that (1) its quiescent current is $12 \mu \mathrm{A}$ (several orders of magnitude lower than conventional regulators); (2) it is adjustable; (3) the input voltage can drop as low as $0.5 \mathrm{~V}$ greater than the output voltage; and (4) it uses switching technology so the voltage drop between input and output does not result in power dissipation. Because of the low operating voltage, the transistor switches are built from a 2N2222 (Motorola Semiconductors, Phoenix, AZ) and a MJE3055T (Motorola Semiconductors, Phoenix, AZ) in a darlington configuration. A "heartbeat" micro-LED is installed on the board to indicate that the board is operating properly. The LED (Hewlett-Packard, Palo Alto, CA) has an internal current-limiting resistor, and its dc current requirement is roughly $1 \mathrm{ma}$. It is programmed to blink for about $15 \mathrm{~ms}$ every $5 \mathrm{~s}$ for an average current consumption under $5 \mu \mathrm{A}$. All components are soldered to a custom circuit board $(5.1 \mathrm{~cm} \times 7.6 \mathrm{~cm})$ which is mounted in a cast aluminum box on standoffs. Four circular, highreliability female connectors for the solenoids and one male connector for the battery connection are mounted on the outside of the box. A hole in the top with a red plastic window allows viewing of the heartbeat LED at low ambient light levels.

The algorithm executed by the microcontroller uses the internal timer and detects when it rolls over. Each rollover decrements counters for two operations, the blinking of the LED and the activation of a solenoid. The program is operated in two modes, normal and fast. In the normal mode, one of four solenoids is activated every 14 days, and in the fast mode, which is used for circuit testing, a solenoid is activated every minute. The modes are selected according to the state of the fifth I/O bit (PB4) at startup. If PB4 is grounded, the fast mode is selected, and if not, the normal mode is selected. The total average current consumption, including LED but exclusive of the solenoid current, was measured to be less than $100 \mu \mathrm{A}$.

The timing system circuit testing was initially conducted in the "fast" mode and allowed to run through numerous sequences to verify that each solenoid driver was operational. Fast mode tests were also conducted with the unit inside a dry-ice-cooled chamber to verify that all components operate over the low end of the temperature range. The variation in timing is dependent on the variation of the crystal frequency from exactly $100 \mathrm{kHz}$, with the timer going off early if the crystal frequency is greater and later if the crystal frequency is less. Table I gives the crystal frequency of two of our timing circuits at $20^{\circ} \mathrm{C}$ and the expected activation time deviation from exactly two weeks, along with the measured activation time deviation while operating at a given temperature. It is clear that the timing system circuit has a small dependence on temperature (insignificant for our purposes) within operational temperatures $\left(0\right.$ to $\left.-30^{\circ} \mathrm{C}\right)$ causing activation to be a few seconds late.

The pneumatic system includes two $6.2 \mathrm{~m}^{3}$ cylinders of compressed dry nitrogen gas, two pressure regulators 
TABLE I. Activation time deviation from exactly two weeks for two circuits (negative time indicates an early activation).

\begin{tabular}{lcc}
\hline \hline & Circuit 1 & Circuit 2 \\
\hline Crystal frequency $(\mathrm{kHz})$ & 100.0013 & 100.0008 \\
Calculated deviation & $-15.7 \mathrm{~s}$ & $-9.7 \mathrm{~s}$ \\
$\quad\left(+20^{\circ} \mathrm{C}\right)$ & $+20 \mathrm{~s}\left(-23^{\circ} \mathrm{C}\right)$ & $+27 \mathrm{~s}\left(-18^{\circ} \mathrm{C}\right)$ \\
Measured deviation at & & \\
operating temperatures & \\
\hline \hline
\end{tabular}

(Tescom Corp., Elk River, MN), two pressure transmitters (SOR, Inc., Lenexa, KS), and four solenoid valves (KIP Inc., Farmington, CT) two of which are connected in parallel to the low pressure ends of each pressure regulator. A schematic diagram of the pneumatic system is given in Fig. 2. Two gas pressure regulators were used for redundancy so that if one malfunctions, microsphere dispersals will continue at 28 day intervals instead of the normal 14 day intervals. The pressure transmitters provide a continuous measurement of system pressure which is recorded hourly by a datalogger (Campbell Scientific, Logan, UT). Pneumatic system pressure provides a log of microsphere dispersal activations by confirming an activation occurred or indicating a system failure. Three microsphere generator units are used to disperse the glass microspheres, and therefore the pneumatic line downstream of each solenoid valve has a three-way manifold branch. The pneumatic lines extending from this branch must be connected to microsphere generator chambers which contain the same color microspheres. Polyethylene tubing [inner diameter (i.d.) $=0.64 \mathrm{~cm}$ and length $=15 \mathrm{~m}$ )] with compression fittings connect the microsphere generator units to the pneumatic system which is buried below the snow surface to minimize snow surface disturbances. The pneumatic system downstream of the pressure regulator is kept at a positive pressure of $400 \mathrm{kPa}$ at all times and each activation of the system is triggered by the timing system circuit opening a solenoid valve. During activation, nitrogen

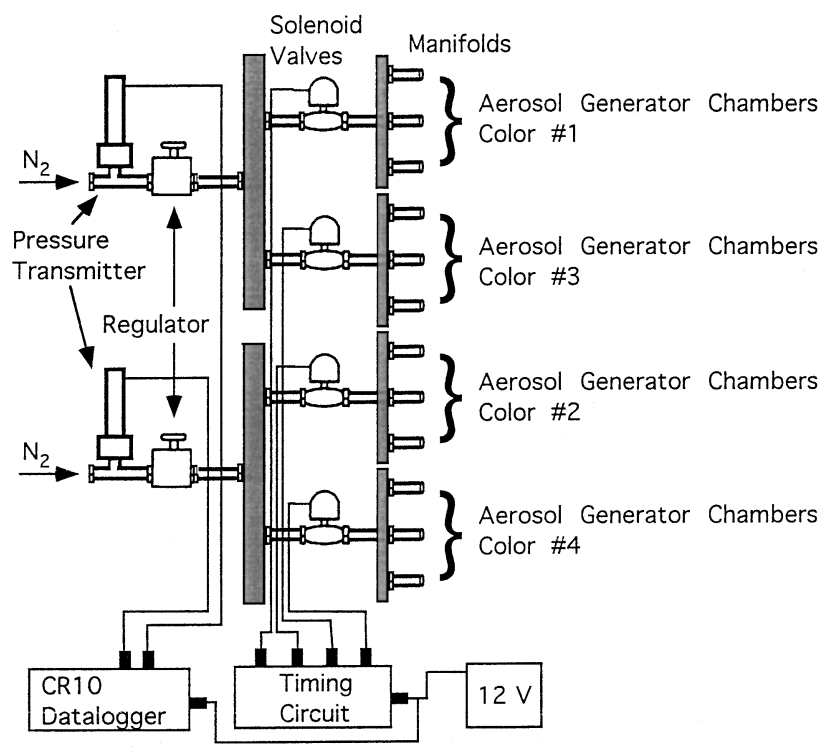

FIG. 2. Schematic diagram of the pneumatic system of the microsphere dispersal system.
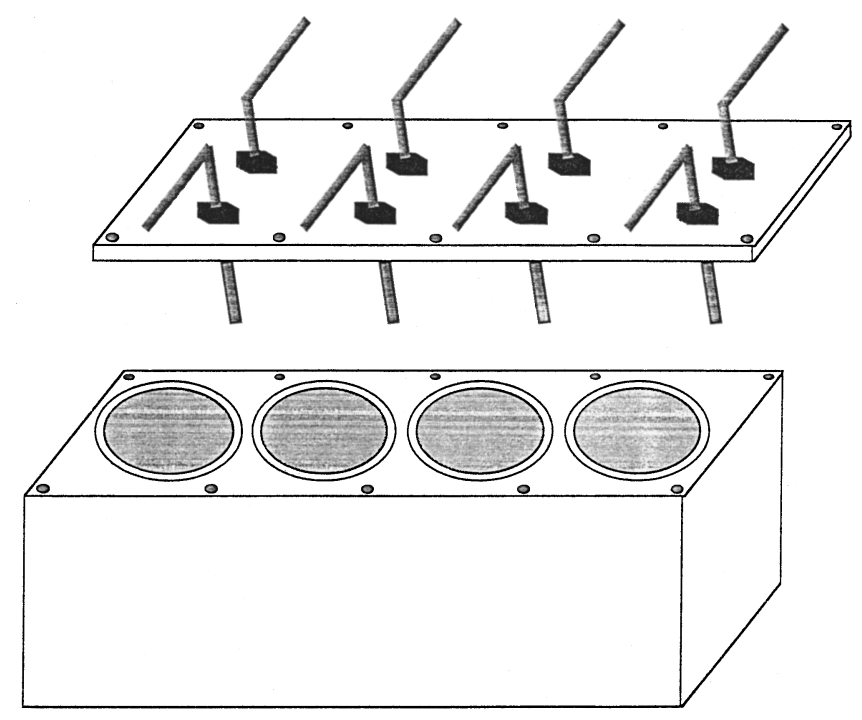

FIG. 3. Schematic diagram of a microsphere generator unit.

gas with a volumetric flow rate of $1700 \mathrm{~cm}^{3} / \mathrm{s}$ is transferred to a chamber in each microsphere generator unit.

Figure 3 provides a schematic diagram of a microsphere generator unit which disperses the tracer material used to assess snow accumulation and transport dynamics. The microsphere generator consists of an aluminum block $(39 \mathrm{~cm} \times 10.2 \mathrm{~cm} \times 9.5 \mathrm{~cm})$ with four circular chambers $(8.6$ $\mathrm{cm}$ diameter and $8.3 \mathrm{~cm}$ deep), and an aluminum cover $(0.64$ $\mathrm{cm}$ thickness) with brass inlet and outlet ports (i.d. $0.47 \mathrm{~cm}$ ) for each chamber mounted with compression-type pipe adapters. The lower two-thirds of each chamber contains $\sim 300 \mathrm{ml}$ of a single color of No. 13 glass microspheres (Potters Industries Inc., Parsippany, NJ) with diameters which range between 106 and $150 \mu \mathrm{m}$, and a density of $2.5 \mathrm{~g} / \mathrm{cm}^{3}$. Microspheres with high reflectivity (albedo) colors are used to minimize solar radiation absorption, and include colors such as pink, light green, orange, and yellow. Compressed nitrogen gas enters the chamber through the inlet port and generates a gas-microsphere aerosol which exits through the outlet port. When assembled, the inlet and outlet port tubing extends 1.9 and $0.6 \mathrm{~cm}$, respectively, into each chamber, and a high pressure seal is maintained using $8.9 \mathrm{~cm}$ diameter buna o-rings.

\section{RESULTS AND DISCUSSION}

Each microsphere generator is mounted at the end of a $1.8 \mathrm{~m}$ cross bar which is supported at a height of $1-1.5 \mathrm{~m}$ over the snow surface by a telescoping $5.1 \mathrm{~cm}$ diameter steel pipe, anchored by an aerodynamic mast of $6.0 \mathrm{~cm}$ diameter steel pipe $2.4 \mathrm{~m}$ in length. A $2.5 \mathrm{~cm}$ diameter, $2.4 \mathrm{~m}$ long steel pipe is mounted at the opposite end of the cross bar from the microsphere generator to keep the mast assembly from rotating in the horizontal plane. The three microsphere generators are spaced a few meters from each other to assure that microspheres will be deposited within the study area regardless of wind speed and direction at the time of activation. 


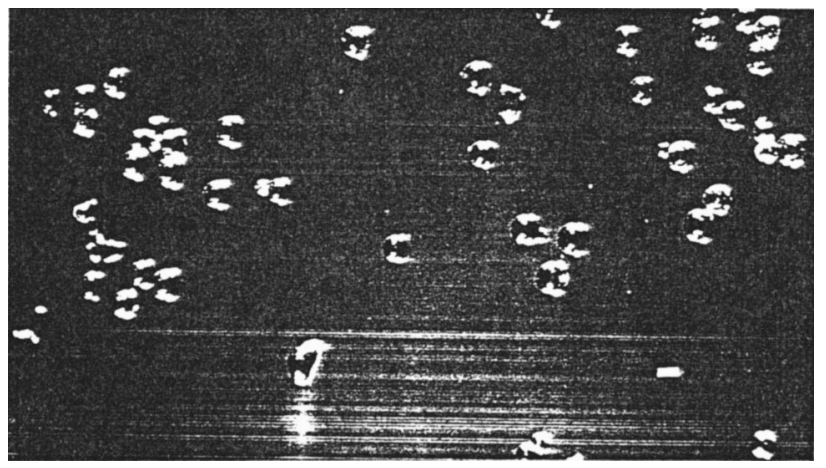

FIG. 4. Low power optical image of colored glass microspheres. Bar: 100 $\mu \mathrm{m}$.

During each $10 \mathrm{~s}$ MDS activation, approximately $25 \mathrm{ml}$ of glass microspheres $\left(\sim 1.5 \times 10^{7}\right.$ individual spheres $)$ are dispersed by each microsphere generator, and have a terminal settling velocity of $0.9 \mathrm{~m} / \mathrm{s}$ resulting in a rapid fall to the snow surface. The initial deposition location of microspheres from each activation is initially estimated using available wind speed and direction measurements at the time of activation and using a known microsphere distribution under calm conditions. ${ }^{13}$ Any snow or rime ice covering the nozzle before activation is shattered by the $400 \mathrm{kPa}$ head pressure of the pneumatic system. A total of four different colors (pink, green, orange, and yellow) are used by MDS, each dispersed during successive 14 day periods, therefore, any given microsphere color is dispersed in a 56 day cycle. Once on the snow surface, the microspheres can either stick to large individual snow grains $(>300 \mu \mathrm{m})$ by large contact adhesion forces, or individually simulate small snow grains. Additionally, at the start of each field deployment of MDS, yellow flat glass shards $(150-425 \mu \mathrm{m})$ are dispersed by hand onto the snow surface to allow an unambiguous identification of the base of the accumulation layer.

Recovery and interpretation of the colored microsphere tracers can be conducted anytime after the first activation, but it must be conducted before any significant melting of the snowpack occurs. For polar ice sheets which rarely experience any significant melting, recovery of microspheres may be conducted at any time. Microsphere recovery is accomplished by extracting snow cores and by sampling along the wall of a snow pit. Shallow snow cores $0.8 \mathrm{~m}$ in length and $0.0045 \mathrm{~m}^{2}$ in cross-sectional area can be extracted using a snow auger. Snow cores provide an overview of the on-site microsphere spatial distribution integrated over the entire accumulation period and can be compared to an expected distribution obtained using wind speed and wind direction data from the time of dispersal. Snow pit sampling provides the most detailed information on microsphere vertical distribution, and is accomplished by excavating a small trench and extracting snow samples from the trench wall with disposable square (i.d. $1 \mathrm{~cm}^{2}, 4.5 \mathrm{~cm}$ length) polystyrene cuvettes (Markson Science, Hillsboro, OR). Analysis of snow core and cuvette snow samples is accomplished by melting the sample, filtering the meltwater, and examining the filter with a low power microscope to determine if microspheres are present. The microspheres are very distinct when viewed
TABLE II. Summary of confirmed system activations for a MDS winter deployment in Antarctica.

\begin{tabular}{ccc}
\hline \hline Activation date & $\begin{array}{c}\text { System pressure } \\
\text { change }(\mathrm{kPa})\end{array}$ & $\begin{array}{c}\text { Microsphere color } \\
\text { dispersed }\end{array}$ \\
\hline $2 / 15 / 95$ & 128.5 & Pink \\
$3 / 1 / 95$ & 153.0 & Green \\
$3 / 15 / 95$ & 128.5 & Orange \\
$3 / 29 / 95$ & 140.8 & Yellow \\
$4 / 12 / 95$ & 104.0 & Pink \\
$5 / 10 / 95$ & 116.3 & Orange \\
$5 / 24 / 95$ & 116.3 & Yellow \\
$6 / 7 / 95$ & 61.2 & Pink \\
$7 / 5 / 95$ & 67.3 & Orange \\
$8 / 2 / 95$ & 67.3 & Pink \\
$8 / 30 / 95$ & 61.2 & Orange \\
$9 / 27 / 95$ & 67.3 & Pink \\
$10 / 25 / 95$ & 67.3 & Orange \\
\hline \hline
\end{tabular}

with a low power microscope as shown in Fig. 4, and are easily distinguished from soil particles or dust by their size, shape (a perfect sphere), and color.

An example of snow accumulation characterization in a wind-swept location in Antarctica illustrates the capabilities of this technique. During a nine month "winter over' period, an MDS unit was deployed adjacent to an automatic weather station on the Ross Ice Shelf, Antarctica. Table II gives the dates of the confirmed activations along with the recorded MDS pneumatic system pressure change and the microsphere color dispersed. These confirmed activations represent $68 \%$ of the total planned for this period, with the missing activations attributed to a malfunctioning pressure regulator. A site map (Fig. 5) shows the locations of the microsphere generators, the snow core samples with microspheres, the snow core samples without microspheres, and the snow pits. Also shown are arrows representing the wind speed and wind direction the winds were coming from during the confirmed microsphere activations. Microspheres were identified in $75 \%$ of the snow cores and were identified in all of the snow pits. A dated snow accumulation profile derived from snow pit sampling is shown in Fig. 6 for the
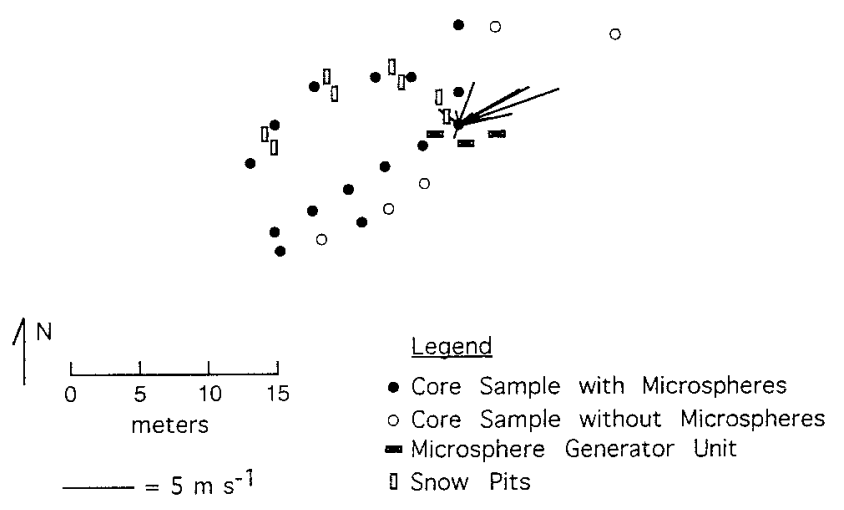

FIG. 5. Site map of the Ross Ice Shelf, Antarctica MDS deployment showing locations of microsphere generators, locations of snow core samples with microspheres, locations of snow core samples without microspheres, snow pit locations, and the wind speed and direction the wind was coming from during confirmed microsphere activations. 


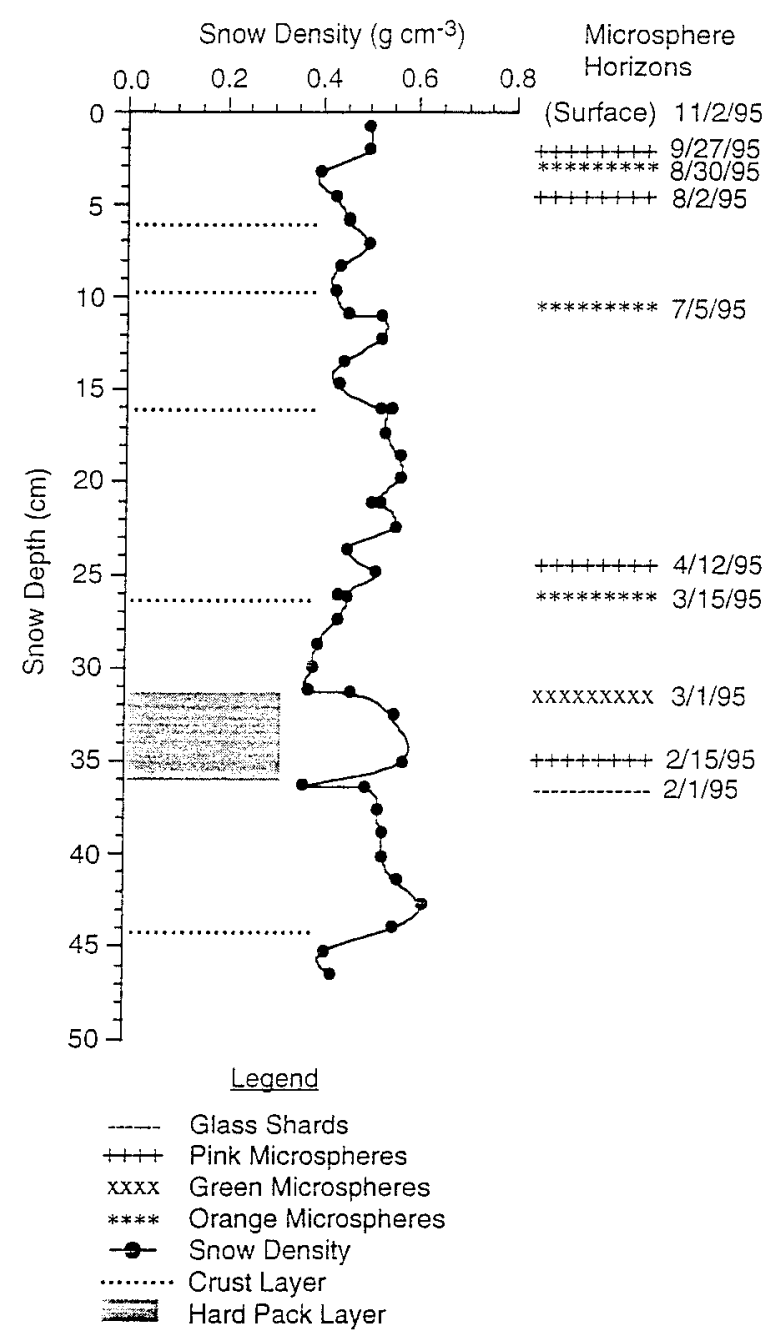

FIG. 6. Structural characteristics of the snow accumulation profile including visually observed crust layers, the presence of a hard pack layer, and the measured snow density profile, as well as the location and dispersal date of colored glass microsphere and glass shard horizons identified in the profile.

period from when flat glass-shards were dispersed (February $1,1995)$ until snow sampling was conducted (November 2, 1995). This profile is a summary of colored microsphere horizons identified in all the snow pits and normalized using a previously described normalization procedure. ${ }^{14}$ Dates are

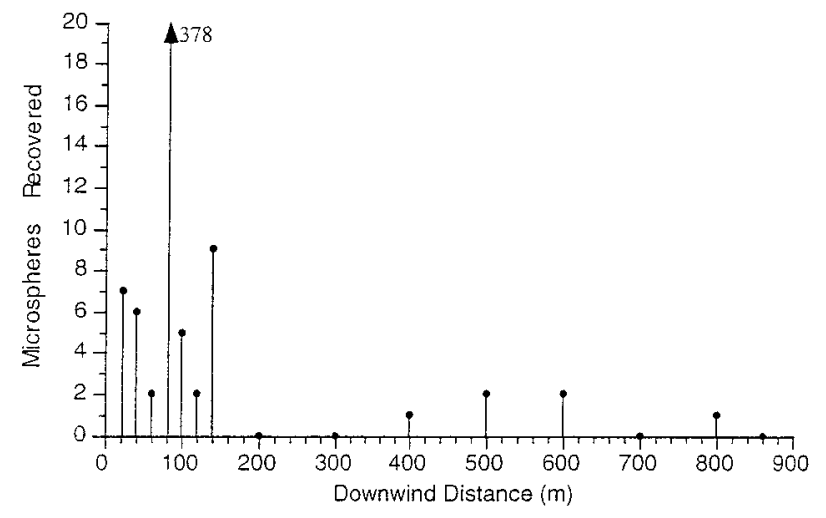

FIG. 7. Results of snow core sampling for microspheres along a $860 \mathrm{~m}$ traverse north of the Ross Ice Shelf, Antarctica MDS deployment site. assigned to each normalized horizon based on the known times for each confirmed dispersal, counting forward in time from the glass shard horizon, and counting back in time from the snow surface at the time of snow pit sampling. With this chronology, structural details of the snow profile identified during snow pit sampling, such as density variations or ice layers, may be more closely linked to a time of formation. Visually observed features in the reference snow pit such as thin crust layers or hard pack layers, and measured snow density as a function of depth are included in Fig. 6.

The characterization of near surface snow grain transport by wind is also possible using microspheres as a tracer. After deposition of the microspheres on the snow surface near the microsphere generators, the microspheres are subject to wind erosion and transport along with snow grains. During this transport process, referred to as saltation, snow grains lift off the surface a few centimeters or less in a near parabolic trajectory (maximum snow grain height reached early in the flight) and impact the surface again possibly dislodging other snow grains. ${ }^{15}$ Forces acting on a saltating snow grain include fluid drag force, and gravitational force. Therefore, for a given lift-off speed and direction, the trajectory length is dependent on both grain size and weight. Saltating snow grains tend to be broken and abraded into particles with rounded corners with a particle density ranging from 500 to $900 \mathrm{~kg} \mathrm{~m}^{-3} .{ }^{16}$ Saltating snow grain size distributions are best represented by a gamma distribution, and show a wide variation of equivalent diameter. Field measurements have shown that equivalent saltating snow grain diameters commonly exceed $0.5 \mathrm{~mm}$ with a mean equivalent diameter of about 0.175 mm. ${ }^{17}$ Compared to snow grains, microspheres have a greater density but are generally smaller, and therefore have a similar saltation trajectory length. This can be illustrated by calculating surface (drag) and body (gravity) forces of microspheres and snow grains launched into a boundary layer flow at a given angle and speed, and calculating the saltation length of each using a previously described integration technique. ${ }^{18}$ For microspheres, a density of $2500 \mathrm{~kg} \mathrm{~m}^{-3}$ and a diameter of $0.120 \mathrm{~mm}$ was assumed. Assuming a snow grain density of $800 \mathrm{~kg} \mathrm{~m}^{-3}$, the snow grain diameter which closely matches the saltation length of a microsphere (less than $1 \%$ difference) is $0.230 \mathrm{~mm}$. For snow grains with a diameter equal to the mean equivalent diameter, the saltation length is shorter than the microspheres saltation length by less than $10 \%$. Of course, microspheres cannot simulate sublimation occurring to the snow grain during transport, but generally sublimation is only important over long transport distances. At an alpine site, it has been estimated that only $13 \%$ of the snow mass is lost to sublimation over a transport distance of $1 \mathrm{~km} .{ }^{11}$

Recovery of microspheres transported from the MDS site by saltation during deployment period (Table II) was conducted one week prior to the snow pit sampling described above. Fifteen snow cores were extracted along a $860 \mathrm{~m}$ traverse north of the MDS site, which was a common downwind direction during the deployment period. Figure 5 shows that none of the microsphere dispersal events were associated with winds blowing along the traverse axis. Figure 7 shows 
the number of microspheres found in each core sample as a function of distance from the MDS site, showing that microspheres were sampled as far as $800 \mathrm{~m}$ from the dispersal site. These results confirm that the MDS system and analysis protocols are capable of characterizing snow grain saltation transport using a tracer, and illustrate the ability of the method to characterize very low tracer concentrations.

\section{ACKNOWLEDGMENTS}

The authors thank J. Nordeng for machining all components, J. Mericle for assembling electronic components, T. Peters for code development and microprocessor programming, and the helpful suggestions and comments of an anonymous reviewer. This research was supported by the National Science Foundation.
${ }^{1}$ G. H. Miller and A. de Vernal, Nature (London) 355, 244 (1992).

${ }^{2}$ L. B. Laird, H. E. Taylor, and V. C. Kennedy, Environ. Sci. Technol. 20, 275 (1986).

${ }^{3}$ M. Sturm, Arctic Alpine Res. 24, 145 (1992).

${ }^{4}$ S. C. Colbeck, Rev. Geophys. 29, 81 (1991).

${ }^{5}$ K. Kosugi, K. Nishimura, and N. Maneno, Boundary-Layer Meteorol. 59, 59 (1992).

${ }^{6}$ N. Maeno, R. Naruse, K. Nishimura, I. Takei, T. Ebinuma, S. Kobayashi, H. Nishimura, Y. Kaneda, and T. Ishida, Ann. Glaciol. 6, 63 (1985).

${ }^{7}$ S. Kobayashi and T. Ishida, Boundary-Layer Meteorol. 16, 35 (1979).

${ }^{8}$ Campbell Scientific, Logan, UT.

${ }^{9}$ R. B. Alley, J. Glaciol. 34, 283 (1988).

${ }^{10}$ W. F. Budd, W. R. J. Dingle, and U. Radok, Studies in Antarctic Meteorology-Antarctic Research Series (American Geophysical Union, Washington, DC, 1966), Vol. 4, p. 71.

${ }^{11}$ R. A. Schmidt, Boundary-Layer Meteorol. 23, 223 (1982).

${ }^{12} \mathrm{G}$. Wendler, Glacier Fluctuations and Climate Change (Kluwer Academic, Dordrecht, 1989), p. 261.

${ }^{13}$ D. A. Braaten, Atmos. Environ. 29 (1995).

${ }^{14}$ D. A. Braaten, J. Geophys. Res. 102, 30047 (1997).

${ }^{15}$ R. J. Kind, J. Wind Eng. Ind. Aerodynamics 36, 855 (1990).

${ }^{16}$ J. D. Iversen, ASCE Proc. 105, 737 (1979).

${ }^{17}$ R. A. Schmidt, Boundary-Layer Meteorol. 34, 213 (1986).

${ }^{18}$ R. S. Anderson and P. K. Haff, Acta Mech. 1, 21 (1991). 